\title{
Fabrication and Evaluation of Silica Aerogel-Epoxy Nanocomposites: Fracture and Toughening Mechanisms
}

\author{
Saeed Salimian ${ }^{1,2}$, Wim J. Malfait ${ }^{2}$, Ali Zadhoush ${ }^{1 *}$, Zahra Talebi $^{1}$, Mohammadreza Naeimirad $^{3}$ \\ ${ }^{1}$ Department of Textile Engineering, Isfahan University of Technology, Isfahan 8415683111, Iran \\ 2 Building Energy Materials \& Components, Empa, Swiss Federal Laboratories for Materials Science and \\ Technology, CH-8600 Dübendorf (Switzerland) \\ ${ }^{3}$ Department of Materials and Textile Engineering, Faculty of Engineering, Razi University, Kermanshah, Iran
}

* Corresponding author’s E-mail: zadhoush@cc.iut.ac.ir

\begin{abstract}
Silica aerogel is a promising candidate for improving the mechanical properties of epoxy-based nanocomposites due to the unique properties such as the 3-dimensional nanoporous structure and high surface area. In this study rheological, mechanical and thermal properties of the silica aerogel-epoxy nanocomposites were investigated. The rheological results demonstrated an increase in viscosity of the nanocomposite suspension compared to the neat resin. The results of dynamic mechanical along with the thermal analysis showed that the addition of $6 \mathrm{wt} \%$ of silica aerogel causes the storage modulus and glass transition point ( $\mathrm{Tg}$ ) to be increased by $11 \%$ and $5{ }^{\circ} \mathrm{C}$, respectively. Also, significant improvements in the elastic modulus (35\%), tensile strength $(62 \%)$ and toughness $(126 \%)$ were achieved with the optimal volume fraction of silica aerogel (6 wt $\%)$. Two main fracture mechanisms were involved in the fracture behavior of the silica aerogel-epoxy nanocomposite: (a) crack pining and deflection, and (b) plastic deformation (debonding).
\end{abstract}

Keywords: Silica aerogel, Nanocomposite, Mechanical properties, Fracture Mechanism, AFM-IR.

\section{Introduction}

Nowadays, inorganic nanoparticles-reinforced polymer nanocomposites have been widely used in engineering applications due to the possibility of improving the mechanical, thermal, electrical and self-healing properties [1-4]. Nanoclays, silica nanoparticles, and carbon nanotubes (CNTs) are commonly utilized as reinforcing agents for a variety of polymer systems [5-8]. However, several processing challenges eliminate the potential benefit of employing nanostructured particles. These challenges include: (1) aggregation and (2) the poor interfacial interaction between polymer and reinforcement [9-12]. In order to overcome to these two challenges, surface functionalization of 
nanoparticles have been carried out to improve dispersion and increase interfacial adhesion with polymer matrix elsewhere [13, 14]. Despite the advantages of using surface modifiers, there are disadvantages to these approaches, such as hydrolysis of silane coupling agents in the oral environment for dental nanocomposites [15], decrease the aspect ratio of CNTs due to the formation of numerous defects on both sidewalls and tip-ends of CNTs [16] and finally, increasing the reinforcement cost.

Recently, the introduction of mesoporous silica for reinforcement in polymer nanocomposites has received a great deal of interest due to the potential to solve the problems of aggregation and poor interfacial interaction [17]. Mesoporous silica has high internal surface area and uniform nanoscale pore sizes which makes them a good candidate for polymer reinforcing and preparation of new polymer nanocomposite materials $[18,19]$. They present stable 3D framework structures which provide confinement effects of polymer intrusion into nanopores [20]. These unique structures can resist to the forces conducted by intercalated polymers, which tend to break up the inorganic material. Various types of polymers including, poly methyl methacrylate [21], polystyrene [22], polyethylene [23], polypropylene [24], polyimide [25], polyaniline [26], polypyrrole [27] etc. have been reported as matrices, reinforced with mesoporous silica. Among the various polymer composites, epoxy-based systems are increasingly used as the matrix of mesoporous silica-reinforced composite materials [28]. It has been established that incorporation of mesoporous silica into the epoxy polymer can increase their modulus and toughness [29]. Jiao et al. [30] noticed that the larger pore volume of mesoporous silica provides more strength and fracture toughness enhancement in epoxy nanocomposites. Kiba et al. [31] introduced novel low thermal expansion materials using mesoporous silica particles incorporated in epoxy composite.

Also, silica aerogels are ultra-lightweight mesoporous materials composed of up to 99.98 vol.\% of porosity (air) and less than $10 \%$ solid silica in the form of highly cross-linked 3D network structures $[32,33]$. Silica aerogel with its high surface area $\left(800-1000 \mathrm{~m}^{2} \cdot \mathrm{g}^{-1}\right)$, pore size of 2-50 $\mathrm{nm}$ and large meso-pore volume of $\left(1.5-4.5 \mathrm{~cm}^{3} \cdot \mathrm{g}^{-1}\right)$ is comparable to that of mesoporous silica. Therefore, silica aerogel has many potential applications in reinforcement of polymer nanocomposites [34, 35]. Aerogel-epoxy system was proposed for thermal insulation property by Ge et al. [36]. They reported that the presence of aerogel reduces the thermal conductivity of epoxy composite drastically. Gupta et al. [37] studied the compressive strength of the epoxy-aerogel nanocomposite and their results show low compatibility between silica aerogel and epoxy resin. Recently, Salimian et al. [38] compared the reinforcement effect of silica aerogel with various surface chemistry including hydrophobic and hydrophilic silica aerogel. They reported that for both types of aerogel surface chemistry, the addition of minor amounts of silica aerogel leads to a strong increase of application relevant properties, e.g. fracture toughness and energy, impact strength, $\mathrm{Tg}$, and storage modulus.

Since the mechanical performance of polymer nanocomposites are impressed by their rheological properties which is affected by the filler structure and content, the aim of the present work is to investigate the mechanical, rheological and thermal properties of epoxy nanocomposites reinforced by silica aerogel with mesoporous structure as a filler with a particular emphasis on identifying fundamental structure-property relationships. Moreover, the mechanisms that contribute to the fracture behavior are investigated by studying the fracture surface of the toughened silica aerogelepoxy nanocomposites. 


\section{Experimental}

\subsection{Materials}

Hydrophobic silica aerogel with a $\sim 20 \mathrm{~nm}$ pore diameter and particle size 2-40 $\mu \mathrm{m}$ was sourced from Cabot Corporation (USA). Epoxy resin was a diglycidyl ether of bisphenol A (DGEBA, trade name EpiKote 828 LVEL) and were purchased from Momentive (USA). It had a mass per amount of epoxide groups of $5.4 \mathrm{~g} / \mathrm{mol}$. Methyl-tetrahydrophthalic anhydride curing agent (MTHPA, Epikure 3601) and 1-methylimidazole (Epikure TM Catalyst 201) catalyst were sourced from Momentive (USA). The structure formulas of the DGEBA, curing agent and catalyst are given in the Figure S1 (Supplementary information).

\subsection{Fabrication of Silica Aerogel-Epoxy Nanocomposites}

A detailed procedure for the composite synthesis can be found in Salimian et al. [38]. A calculated amount of silica aerogel (1-6 wt\%) was suspended in 100 part of epoxy resin using mechanical mixer. Hardener and catalyst were added weight ratio of 89.2 and 2 parts per hundred mass parts of DGEBA resin and mixed by high-speed shear mixing $\left(5000 \mathrm{~m} \cdot \mathrm{min}^{-1}\right)$ under vacuum and $75^{\circ} \mathrm{C}$, achieving a homogeneous dispersion of silica aerogel in epoxy matrix and removing bubbles. The final mixture was poured into a waxed-steel mold and cured by heating at $80^{\circ} \mathrm{C}$ for $4 \mathrm{~h}$. The cured sheets were demolded and then post-cured at $160^{\circ} \mathrm{C}$ for $1 \mathrm{~h}$ to complete the curing cycle. A schematic illustration of the sample preparation is shown in Figure S2.

\subsection{Characterization}

\section{Morphology}

$\mathrm{N} 2$ adsorption/desorption measurements were performed at $77 \mathrm{~K}$ on TriFlex Micromeritics instrument. The sample was outgassed for $12 \mathrm{~h}$ at $250^{\circ} \mathrm{C}$ and $0.016 \mathrm{mmHg}$. The specific surface area was calculated by the Brunauer-Emmett-Teller (BET) method and the total pore volume was estimated from the adsorbed amount at a relative pressure of 0.99. Pore size distribution curves determined by applying the $\mathrm{BJH}$ model to the adsorption isotherms.

Scanning electron microscopy (SEM) was used to visualize the fracture surfaces of specimens, which were coated with a thin layer of platinum $(\sim 4 \mathrm{~nm})$ and observed using a FEI Nova NanoSEM 230 instrument (USA) at an accelerating voltage of $10 \mathrm{kV}$.

Atomic force microscopy images were collected using a nanoIR2-FS system (Anasys Instruments, USA) operating in peakforce tapping mode using a gold coated probes (nominal spring constant 2 $\mathrm{N} / \mathrm{m}$, nominal resonant frequency of $80 \mathrm{kHz}$, Bruker). 


\section{Rheology}

The steady-state viscosity was performed using Paar Physica MCR 300 rheometer (Austria). The steady-state viscosity measurements were carried out in the shear rate range from 0.1 to $1000 \mathrm{~s}^{-1}$ using plate-plate geometry $\left(25 \mathrm{~mm}\right.$ in diameter with $1 \mathrm{~mm}$ gap) at $22^{\circ} \mathrm{C}$. All samples were pre-sheared by a time sweep under low deformation (strain $0.1 \%, 1 \mathrm{~Hz}$ ).

\section{Mechanical}

The determination of tensile strength, tensile modulus, yield stress, strain-at-break and work of rupture was performed at ambient temperature according to ASTM D638 [39] using a Universal Testing System Z010 (Zwick, Germany) equipped with a 10KN load cell. The dumbbell-shaped specimens were machined by water-jet cutting to geometry of $75 \mathrm{~mm}$ long in the narrow region, 2-3 $\mathrm{mm}$ thick, and $10 \mathrm{~mm}$ wide along the center of the casting for composite and their sides and edges were polished to remove possible defects. The cross-head speed was $0.5 \mathrm{~mm} / \mathrm{min}$ at $25^{\circ} \mathrm{C}$. Three replicate tests were performed for the neat epoxy and each of silica aerogel-epoxy composites. Alternatively, toughness was calculated by measuring the surface area from force-displacement curves.

Three-point bending tests were performed on the sample with an initial crack and the fractured surface was used for fractography analysis.

The storage modulus and Tan $\delta$ were determined on a dynamic mechanical analyzer (DMA RSA3, TA Instruments, USA). The samples with dimensions of $3 \times 10 \times 50 \mathrm{~mm}^{3}$ were tested in a shear mode from $22^{\circ} \mathrm{C}$ to $180^{\circ} \mathrm{C}$ at a heating rate of $3{ }^{\circ} \mathrm{C} / \mathrm{min}$ and an oscillation frequency of $1 \mathrm{~Hz}$.

\section{Thermal}

Differential thermogravimetric analysis (DTGA) was conducted with a Perkin-Elmer TGA 8000 (USA) instrument. The Samples were tested under a nitrogen atmosphere from 35 to $900{ }^{\circ} \mathrm{C}$ at a heating rate of $20^{\circ} \mathrm{C} \cdot \mathrm{min}^{-1}$. The thermogravimetric weight loss curve (TG, \%) was recorded as a function of time and temperature.

\section{Result and Discussion}

\subsection{Pore structure and properties of silica aerogel}


Adsorption-desorption isotherms and pore size distribution of the silica aerogel are depicted in Figure 1. The nitrogen sorption isotherm of the silica aerogel shows the IV-type isotherms with a type IV hysteresis loops which is a characteristic feature of mesoporous materials according to the IUPAC classification [40, 41]. From the pore-size distribution, calculated by the BJH method, a narrow pore size distribution is confirmed, despite the known limitations due to sample deformation during nitrogen sorption analysis of aerogels [42]. BET surface areas, average pore width, and total pore volume are $716 \mathrm{~m}^{2} \cdot \mathrm{g}^{-1}, 18 \mathrm{~nm}$ and $5 \mathrm{~cm}^{3} \cdot \mathrm{g}^{-1}$, respectively. Therefore, the pore size of silica aerogel as the filler estimated by the BJH method is sufficiently large for extended epoxy polymer chains to easily incorporate within mesostructure of the filler [43].

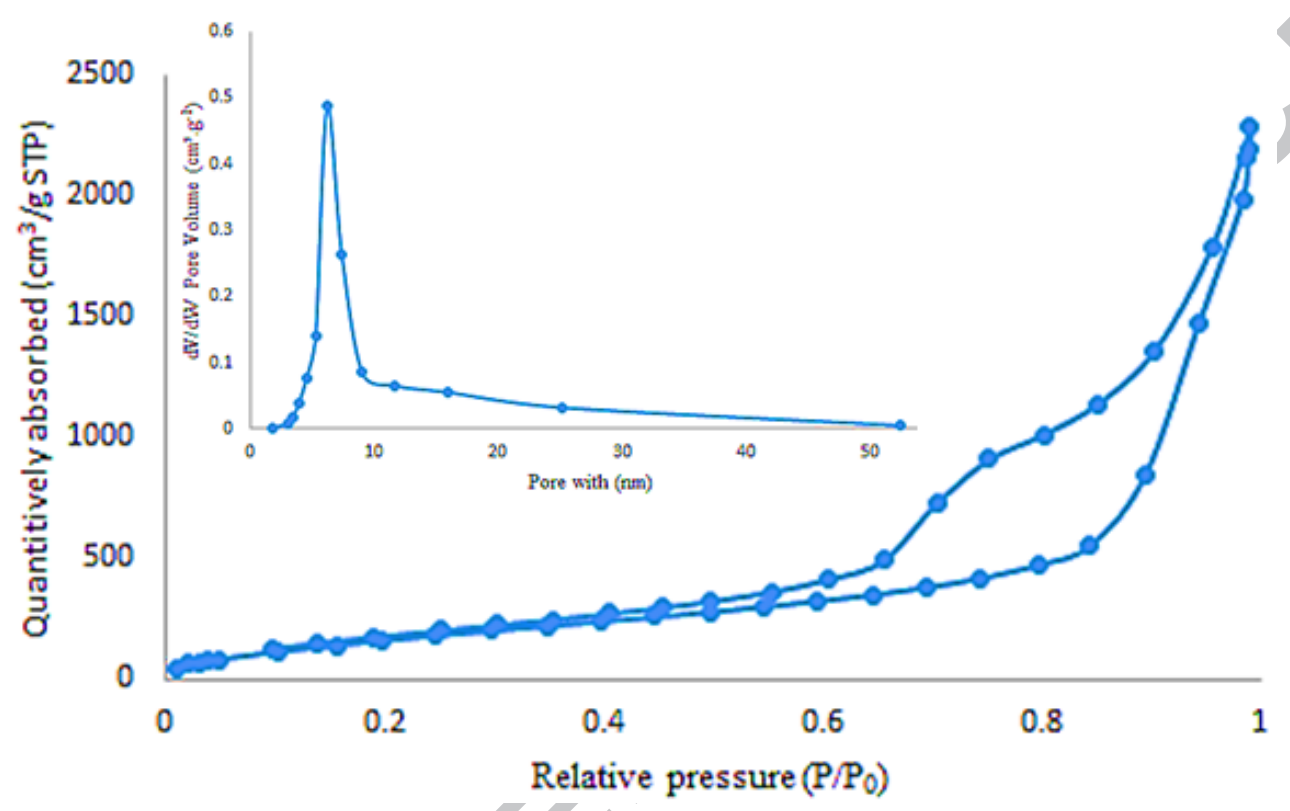

Figure 1. $\mathrm{N}_{2}$ adsorption-desorption isotherm of silica aerogel (Inset image is the pore size distribution calculated by the BJH method.

\subsection{Physical properties of silica aerogel-epoxy nanocomposites}

To estimate how much the amount of the mesopore space is filled with the epoxy polymers, the "dead pore ratio" is theoretically calculated by utilizing the specific gravity of the nanocomposite according to equations 1 and 2 [44].

$V=\frac{\frac{1}{\rho}-\frac{1}{\rho_{\text {polymer }}} \times\left(\frac{100-x}{100}\right)-\frac{1}{\rho_{\text {silica }}} \times\left(\frac{x}{100}\right)}{\left(\frac{x}{100}\right)}$

Dead pore ratio $($ Vol\% $)=\frac{\left(V_{0}-V\right)}{V_{0}} \times 100$

Where $\mathrm{x}$ is the additive amount ratio (wt $\%$ ) of silica aerogel in the composite and $\rho, \rho_{\text {polymer, }}$ and $\rho_{\text {silica }}$ are the density of the composites, polymer and silica $\left(2.18 \mathrm{~g} \mathrm{~cm}^{-1}\right)$, respectively. $\mathrm{V}_{0}$ is the total pore volume of mesoporous silica particles by $\mathrm{N}_{2}$ adsorption-desorption isotherms. When the dead pore ratio is $100 \%$, the polymer fully occupied the mesopores, while the dead pore ratio $0 \%$ means that the mesopore space remains vacant without being filled with polymer. The results show that the specific gravities of the nanocomposites are almost the same as the epoxy polymer alone $\left(\sim 1.19 \mathrm{~g} . \mathrm{cm}^{-3}\right)$ (Table 1). This implies the absence of encapsulated air within the nanocomposite. In addition, it can be speculate that the polymer molecules infiltrate considerable part of the mesopores. For all the nanocomposites the calculated dead pore ratios are higher than $100 \mathrm{vol} \%$. These indications reveal 
that all the mesopores of the silica aerogel are totally filled with epoxy resin. To further verify the physical confinement of the epoxy polymers, the amount of polymers inside of the mesopores are quantitatively calculated according to equation 3 and 4 (Table 1).

Polymer ratio $(w t \%)$ inside $=\frac{V_{0} \times \frac{x}{100} \times \frac{\text { dead pore ratio }(\mathrm{Vol} \%)}{100} \times \rho_{\text {polymer }}}{\left(\frac{100-x}{100}\right)} \times 100$

Polymer ratio (wt\%)outside $=100-$ Ploymer ratio $(w t \%)$ inside

(4)

For the composite with the highest loaded amount of silica aerogel (6\%), it is estimated that around $40 \%$ of the total polymers are embedded inside the mesopores of silica aerogel. Moreover, when the particle loading of the silica aerogel is increased, the estimated polymer inside became dramatically high, which increases from $4.67 \%$ to $39.73 \%$ for $1 \mathrm{wt} \%$ and $6 \mathrm{wt} \%$ of silica aerogel, respectively.

\subsection{Rheological behavior}

Rheological properties provide useful information about processability of the composite material [45]. Figure 2 shows the steady shear viscosity $(\eta)$ as a function of shear rate for neat epoxy and its suspensions with various silica aerogel contents at room temperature. In the suspensions with a silica aerogel loading below of $4 \mathrm{wt} \%$, the viscosity is approximately near to the viscosity of neat epoxy, conversely, above $4 \mathrm{wt} \%$, viscosity increases sharply with adding the silica aerogel content, especially at low shear rates. The increased viscosity compared to the neat epoxy is due to the confinement effect of the silica aerogel on the epoxy polymer chains which causes an inhomogeneous flowing behavior. Moreover, the flow resistance of confinement effect is intensified at high filler content, thereby leading to a higher viscosity. Meanwhile, confinement effect was observed in the spherical silica particles suspended in epoxy resin which is also reported in literature [46]. As the shear rate becomes larger, the difference of viscosity between the suspensions with the neat epoxy becomes diminished due to similar dispersion quality at high shear rate. It can be seen that neat epoxy and all of the silica aerogel nanocomposite suspensions exhibit Newtonian behavior initially which then develop into shear thinning behavior at high shear rates. The Newtonian region can be ascribed to the reinforced resistance to the external stresses caused by the confinement effect of the silica aerogel on polymer chains, while the shear thinning behavior is attributed to the polymer conformation changes under high sheer rates. The same behavior has been observed in the blend of Bis-GMA and TEGDMA filled with the fumed silica [47].

Plots of shear stress $(\ln \tau)$ versus shear rate $(\ln \gamma)$ (Figure S3) give a linear relationship whose slope yields $\mathrm{n}$. The features of the flow curves, can be modeled using Power low (Ostwald) model [48]. Equation 5 shows the mathematical expression for this model.

$\tau=K * \dot{\gamma}^{n}$

Where $\tau$ is shear stress, $\gamma^{\prime}$ is shear rate, $\mu$ is shear viscosity, $\mathrm{K}$ is constant and $\mathrm{n}$ is power law index.

As shown in Figure S3, increasing silica aerogel content causes $\mathrm{n}$ to be decreased, hence indicating silica aerogel-epoxy nanocomposites with more silica aerogel have higher shear-sensitivity. Generally, the suspension with the smaller $n$ value shows the stronger shear sensitivity [49]. It can be seen that the value of $\mathrm{n}$ for all the suspensions is less than 1 , which means the significant shear thinning behavior has dominated the suspension with various filler contents. This is in accordance with rheological behavior of epoxy-clay suspensions [50]. 


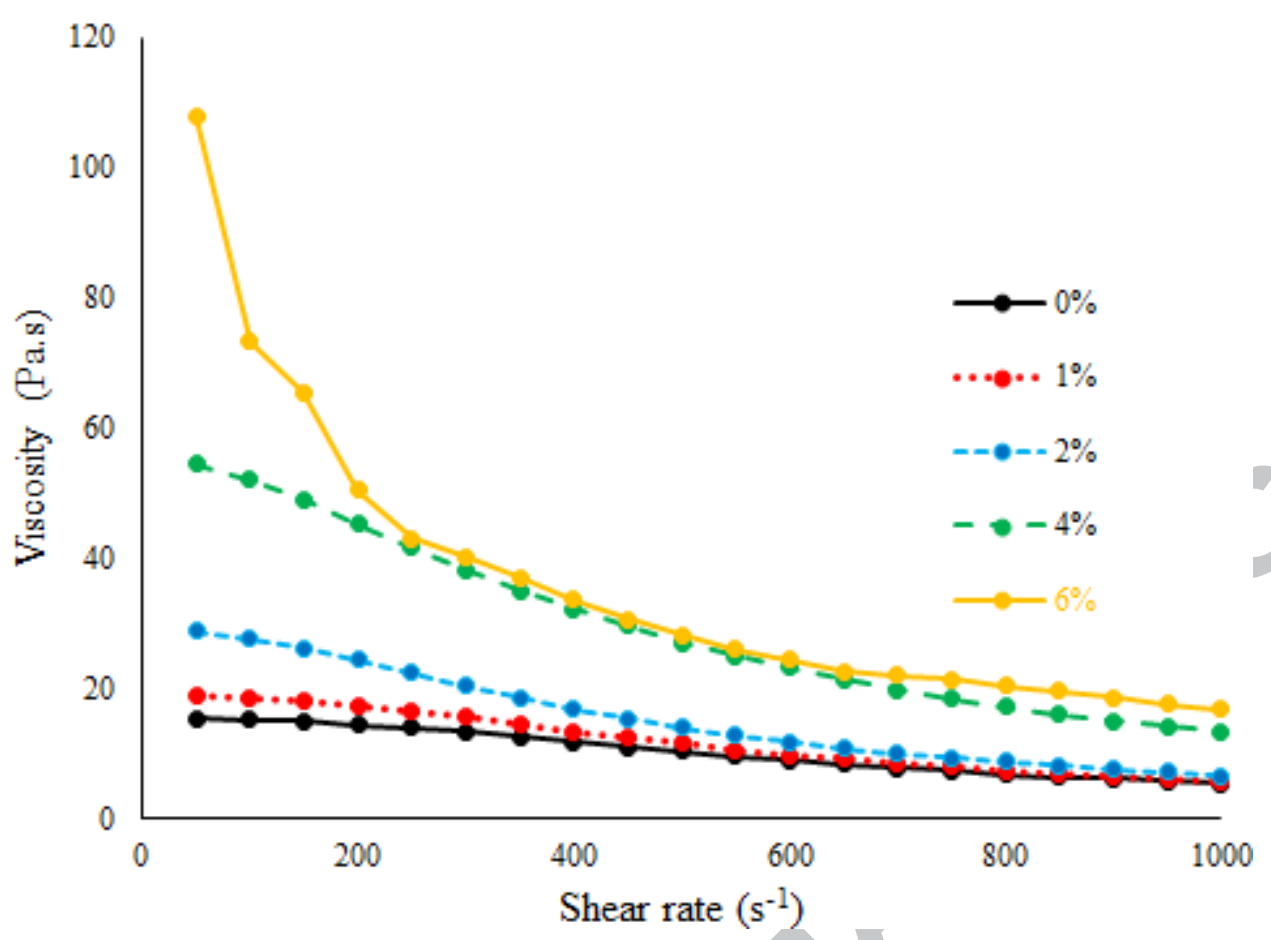

Figure 2. Viscosity versus shear rate for neat epoxy and silica aerogel-epoxy suspensions with various silica aerogel contents (wt\%).

\subsection{Dynamic mechanical and thermal properties}

The dynamic mechanical analysis and the corresponding glass-transition temperatures of silica aerogel-epoxy nanocomposite with different contents of silica aerogel were measured at temperature from 40 to $180{ }^{\circ} \mathrm{C}$ (Figure 3, Table 1). It can be seen in Figure 3a that the storage modulus of silica aerogel-epoxy nanocomposite at $45^{\circ} \mathrm{C}$ (glassy region) is increased from 0.93 to $1.03 \mathrm{GPa}$ as the amount of silica aerogel content increased from $0 \mathrm{wt} \%$ to $6 \mathrm{wt} \%$. Furthermore, the maximum of Tan $\delta$ of the silica aerogel-epoxy nanocomposite slightly shift toward higher temperatures upon the addition of more amounts of silica aerogel indicating a higher $\mathrm{Tg}$ of silica aerogel-epoxy nanocomposite (Figure 3b). Tg of the silica aerogel-epoxy nanocomposite with $6 \mathrm{wt} \%$ silica aerogel is $5.2^{\circ} \mathrm{C}$ greater than that of neat epoxy. This improvement in the dynamic thermomechanical properties of the silica aerogel-epoxy nanocomposite results from the mechanical anchoring of the epoxy polymer chains on the particle and the pore channels of the silica aerogel. This mechanical anchoring effectively constrains the epoxy main-chain motion, thus increasing the storage modulus and $\mathrm{Tg}$ of the composite [51]. 

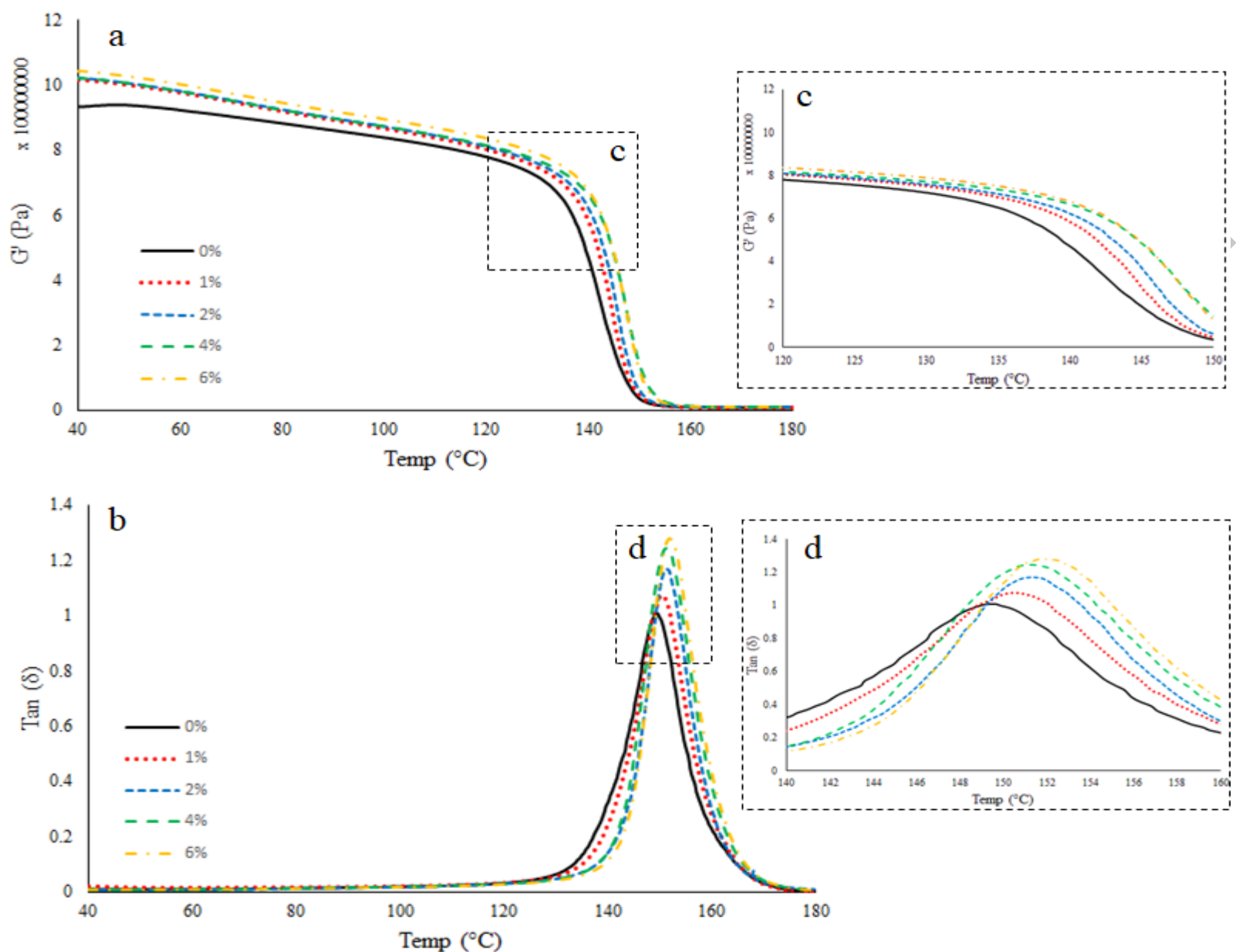

Figure 3. (a) Storage modulus and (b) tan (ס) versus temperature for silica aerogel-epoxy nanocomposite (wt\%), (inset is the zoom on the (c) $120-150^{\circ} \mathrm{C}$, (d) $140-160^{\circ} \mathrm{C}$ range).

Figure 4 provides DTG curves of silica aerogel-epoxy nanocomposite with various silica aerogel contents. The temperature of the maximum degradation rate $\left(\mathrm{T}_{\max }\right)$ obtained from these curves are summarized in Table 1. As shown in Figure 4, all the nanocomposites exhibit higher temperatures at $\mathrm{T}_{\max }$ compared with pristine epoxy suggesting that the decomposition is delayed due to the existence of polymer both inside and outside of the channel of silica aerogel [52]. 


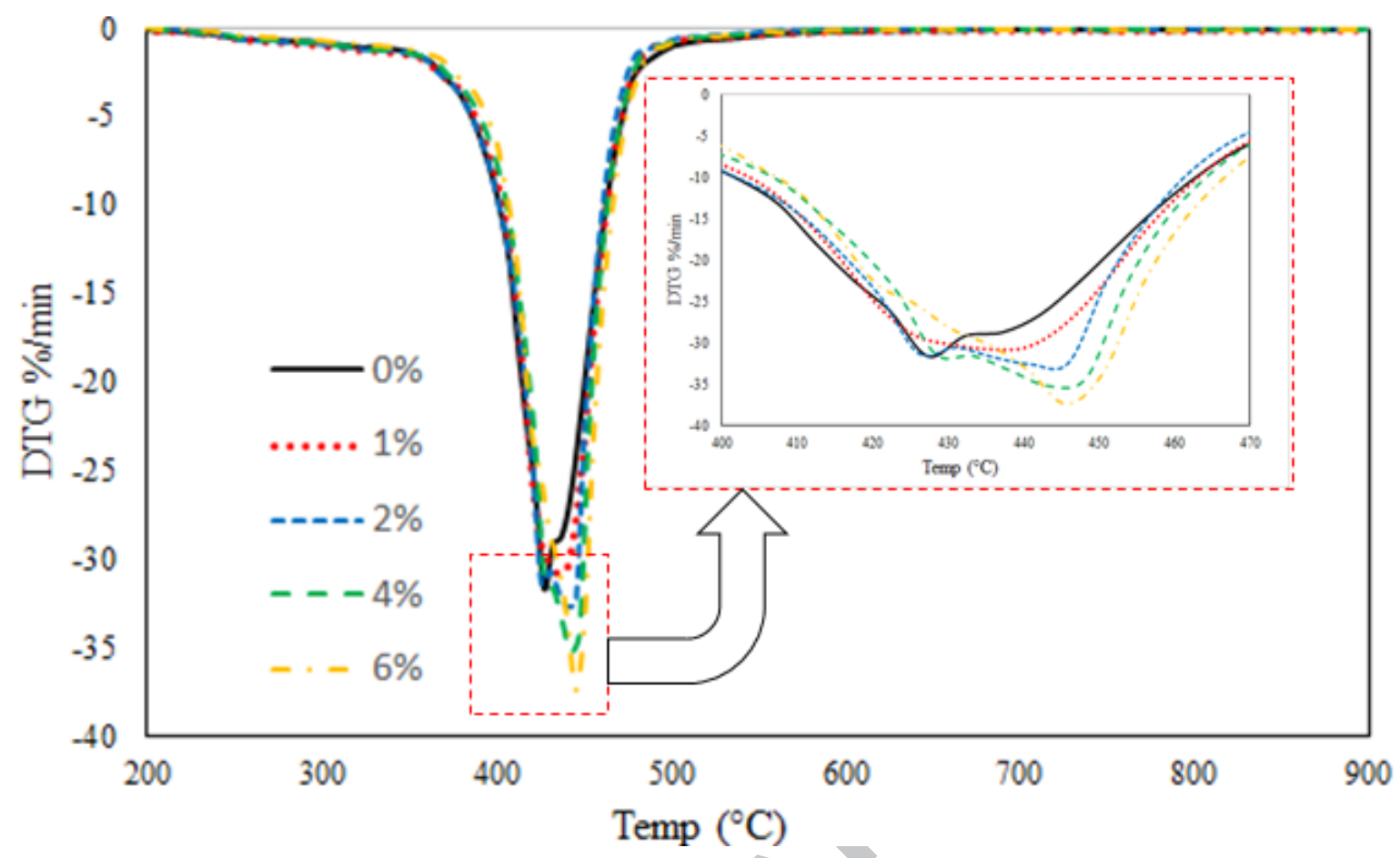

Figure 4. DTG curve of silica aerogel-epoxy at various silica aerogel contents (wt\%). (With scale-up in the 400-470 ${ }^{\circ} \mathrm{C}$ range).

These results suggest that the incorporated silica aerogels into epoxy matrix have an interpenetrating organic-inorganic network (IOIN) where the silica aerogel pores can be considered to be an inorganic network and the epoxy polymers could be introduced into these nanopores. As a result, both the mesoporous silica aerogel and the polymer chains interpenetrate and then form a model of polymer mobility restriction. In other words, an interface layer consisting of entangled polymers is formed inside the aerogel pores, thus, the compatibility between the silica aerogel and epoxy polymer improved significantly. Other studies show the same behavior in other polymer-silica aerogel system [53]. Figure 5 shows the IOIN structure in which the epoxy polymers are penetrated into mesopores of silica aerogel. 


\section{Interpenetrating aerogel-epoxy network}
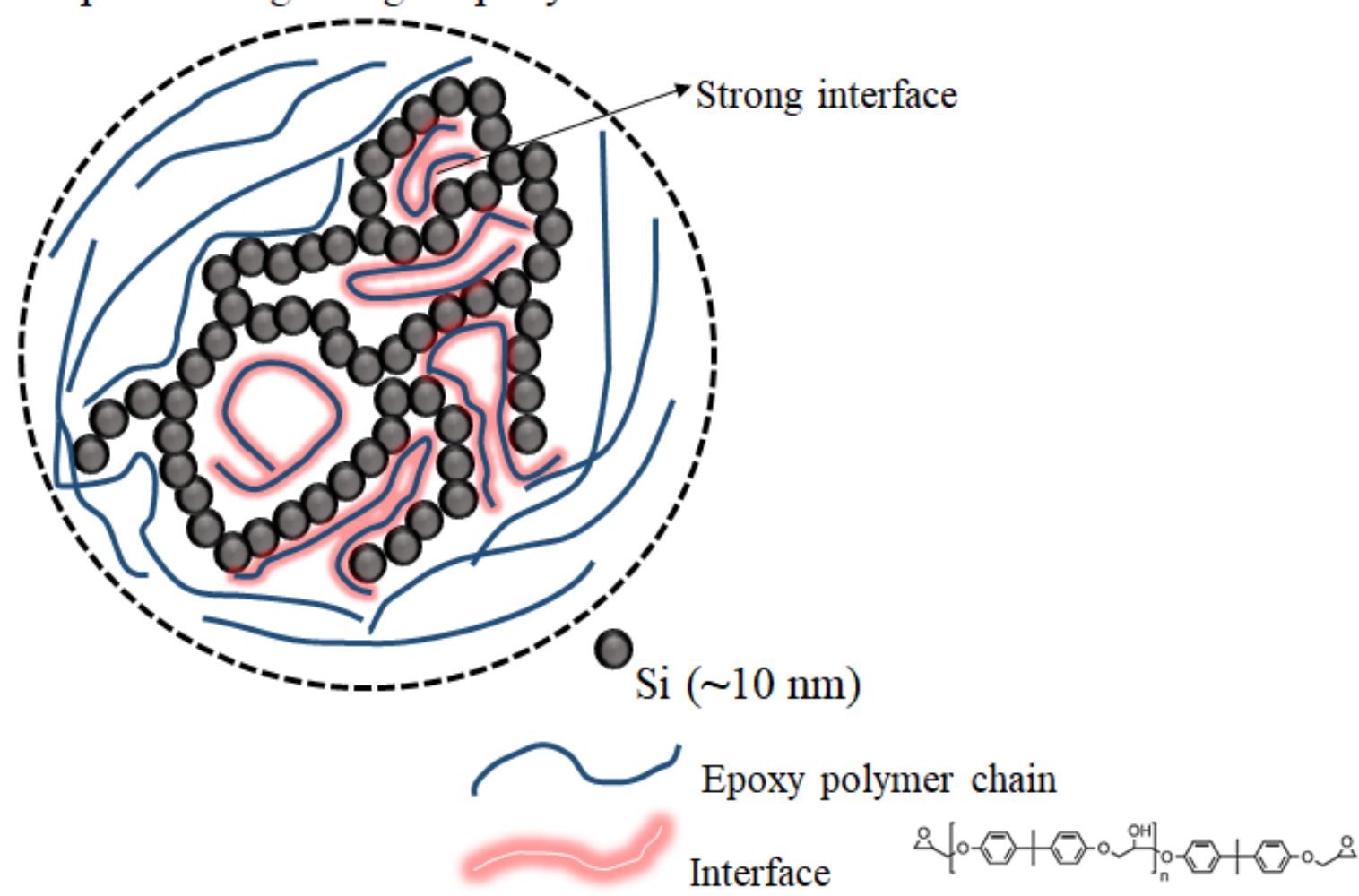

Figure 5. The structural model of the "interpenetrating organic-inorganic network" (IOIN).

\subsection{Mechanical properties}

Tensile testing experiments resulted in different mechanical properties which is illustrated as stressstrain diagram (in Figure S4) and modulus, strength, elongation, and toughness of the silica aerogelepoxy nanocomposites as a function of silica aerogel content are summarized in Figure 6 and Table 1.

Mechanical performance, particularly toughness properties, of the epoxy nanocomposites are increased with increasing silica aerogel content. The modulus, strength, and toughness of the silica aerogel-epoxy nanocomposite at maximum value enhanced by $62 \%, 35 \%$ and $126 \%$, respectively compared to the neat epoxy. The substantial improvement in the mechanical properties for the silica aerogel-epoxy nanocomposites is due to the strong interfacial interactions and adhesion between epoxy matrix and silica mesophase. It is noteworthy that favorable interfacial interactions are achieved in nanocomposite without surface modification of the silica with the organic groups. The high internal surface area and large pore volume of the silica aerogel increase the amount of polymer filling the framework of silica aerogel and leads to improvement in the interfacial interaction between the polymer and the silica pore walls. The increase in modulus (35\%) for epoxy nanocomposite filled with $6 \mathrm{wt} \%$ of silica aerogel is comparable to the benefit in modulus provided by other mesoporous silica reinforcements $[54,55]$. Furthermore, the tensile strength $(62 \%)$ and toughness $(126 \%)$ for the epoxy-aerogel nanocomposite are improved as much as for the previously reported mesoporous silica filled epoxy nanocomposite [30]. Hence, silica aerogel can improve the stiffness of the nanocomposite without scarifying the elasticity and toughness. The improved reinforcement provided by the silica aerogel is due to the effective penetration of the three-dimensional pore network by the epoxy 
polymer resulted in good interfacial interaction. It has been previously shown that nanoporous silica particles with framework pores sizes of $0.3 \mathrm{~nm}$ act as micron size reinforcing agents, similar to nonporous forms of silica [56]. Therefore, the pore size of the silica, mesopores or nanopores, are an important factor which affect the mechanical properties of the nanocomoposite. Furthermore, previously reported rubbery epoxy nanocomposites reinforced by hexagonal mesoporous silica show similar, though not identical, mechanical properties in comparison with our nanocomposites reinforced by silica aerogel [30]. However, the tensile strength and the elongation-at-break for the epoxy-aerogel nanocomposite were not improved as much as for the previously reported for epoxyorganoclay nanocomposites [57].
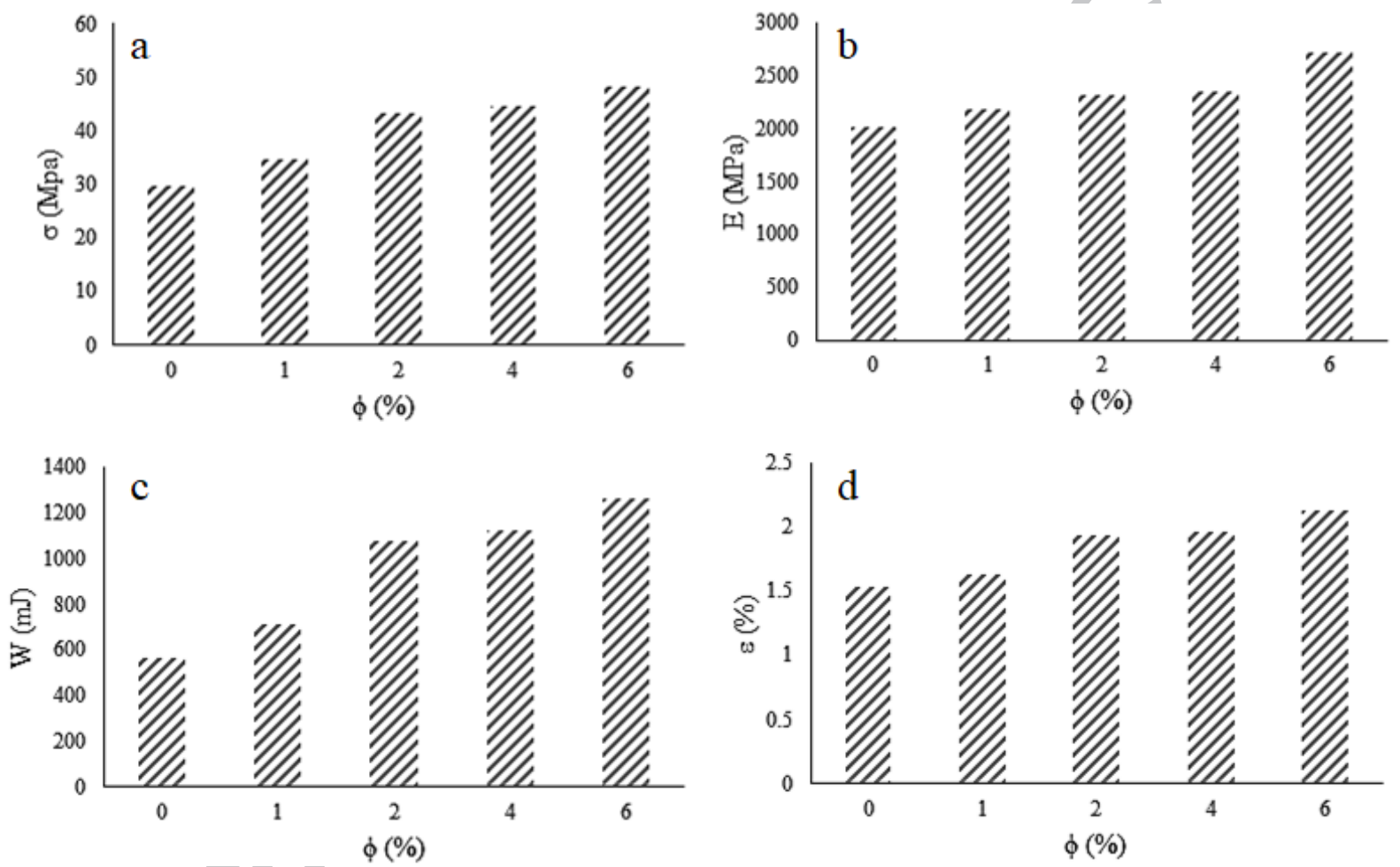

Figure 6. (a) Ultimate tensile strength, (b) Young's modulus, (c) toughness and (d) elongation at break of silica aerogelepoxy nanocomposite versus silica aerogel content (wt.\%).

\subsection{Fractography}

The improvement in the toughening performance was studied by the fractured surfaces of the silica aerogel-epoxy nanocomposite. In a SEM image of the sample with a silica aerogel content of $6 \mathrm{wt} \%$, two main mechanism can be clearly observed to be responsible for the increase in the toughness: (a) plastic deformation of the matrix (debonding) (Figure 7a,b) and (b) crack pinning and deflection (bowing) (Figure 7a,c). Crack pinning and deflection is occurred when the crack front encounters the reinforcing particles and passes between the silica aerogel-epoxy interface and forms micro-cracks $[58,59]$. This means that the crack is propagated through the matrix around the silica aerogel particles due to the good interfacial adhesion between silica aerogel and epoxy. The plastic void growth 
toughening mechanism initiated by the stress concentrations around the silica aerogel followed by the formation of voids, cavities, and debonding effects in the process zone at the crack tip [60].These mechanisms contribute to energy absorption and consequently, the toughness of the nanocomposites increased. These toughening mechanism occur in epoxy-based composites modified with nano structured materials $[61,62]$.
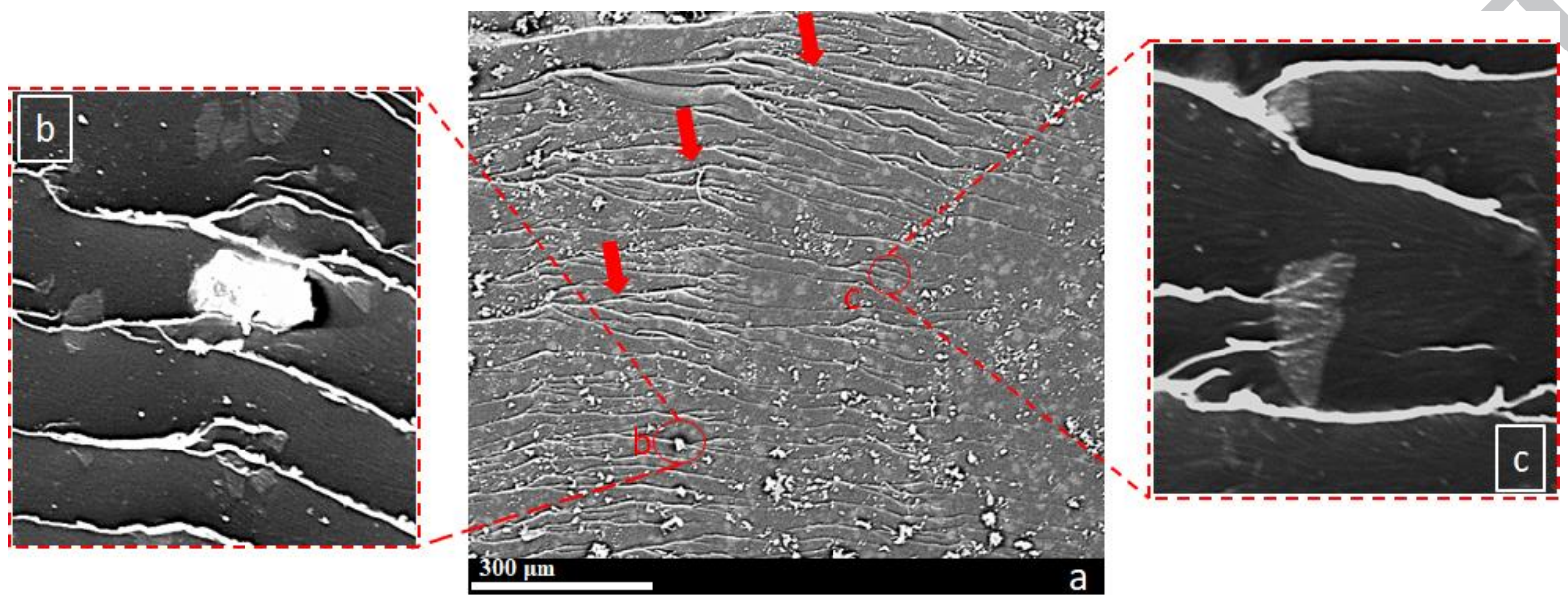

Figure 7. (a) SEM images of the fracture surfaces of silica aerogel-epoxy nanocomposite containing 6 wt\% silica aerogel, showing (b) formation of cavities/debonding (c) crack pining (crack deflection). Red arrows show the formation of river line.

Moreover, the mesoporosity associated with the reinforcing particle might promote the microcrack formation within the particle, however, there is no evidence in support of intraparticle microcracking. It is noteworthy that the epoxy polymer located in the silica aerogel pores as well as on the outer surface promoted reduced cross-linking density regions around the mesopores thus producing the highly flexible interface regions which play a major role in the formation of shear bands close to the silica aerogel particles. In order to verify these shear bands, fracture roughness was determined directly by evaluating the topography image received from 3D AFM-IR on fractured surface of silica aerogel-epoxy nanocomposite (figure 8). These shear bands are located within the silica aerogel grains. Furthermore, the AFM-IR image reveals an increase in the surface roughness at the region that silica aerogel particles present. The roughness of the neat epoxy and epoxy filled with $6 \mathrm{wt} . \%$ of the silica aerogel are respectively 4 and $9 \mathrm{~nm}$. From the SEM images (Figure 9), it can be seen that the highly filled nanocomposites ( $6 \mathrm{wt} \%$ silica aerogel) have a relatively rough appearance with numerous river lines while the fracture surface of the neat epoxy exhibits a relatively smooth surface indicating a typical brittle polymer fracture [63]. The river lines were caused by the crack propagating along different planes at the fracture surface indicating many new surfaces were created during fracture (figure 7 and 9). 


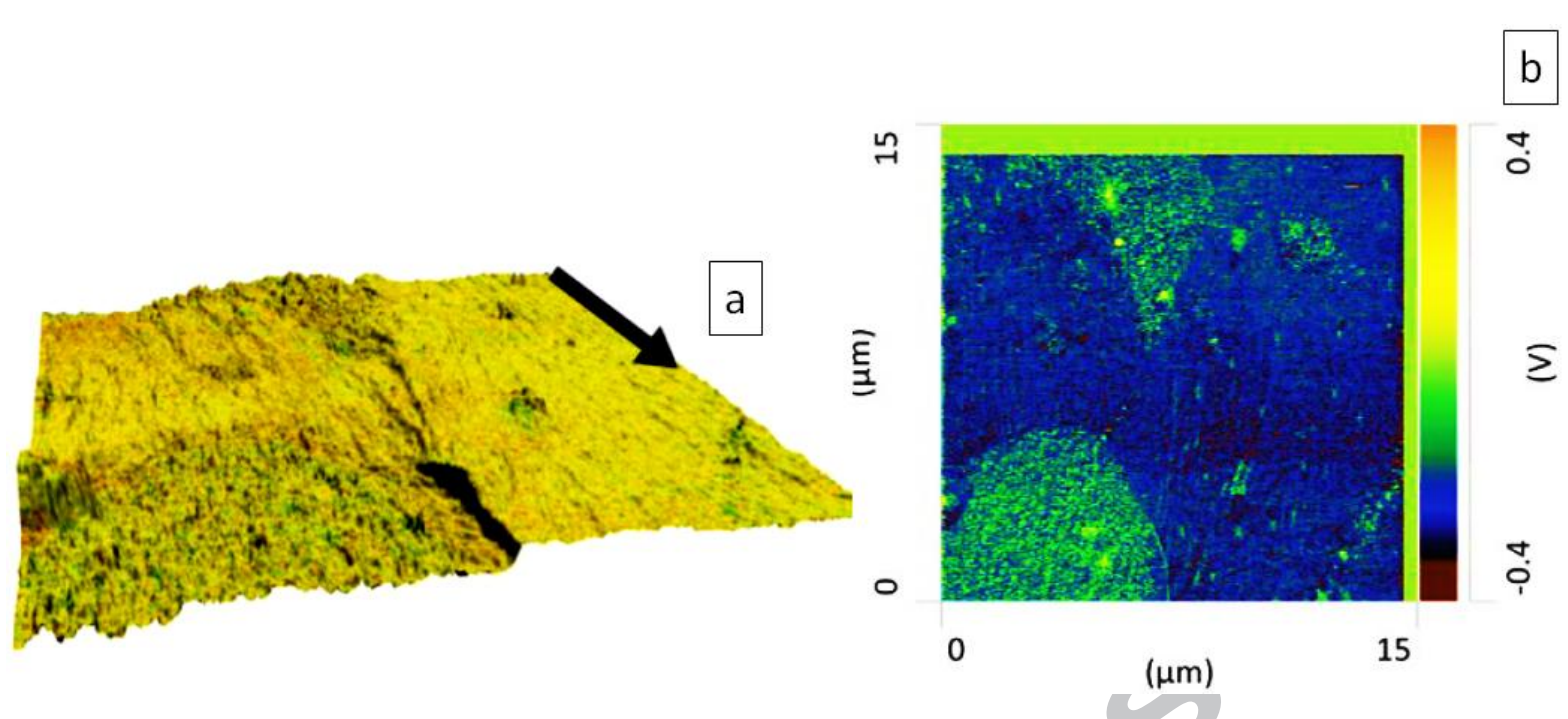

Figure 8. AFM-IR for the fracture surface of the silica aerogel-epoxy (6 wt\%), where the black arrow indicates the direction of the crack propagation. a) $3 D$ view of the topography and b) nanoIR image: (aerogel+epoxy green, neat epoxy blue).
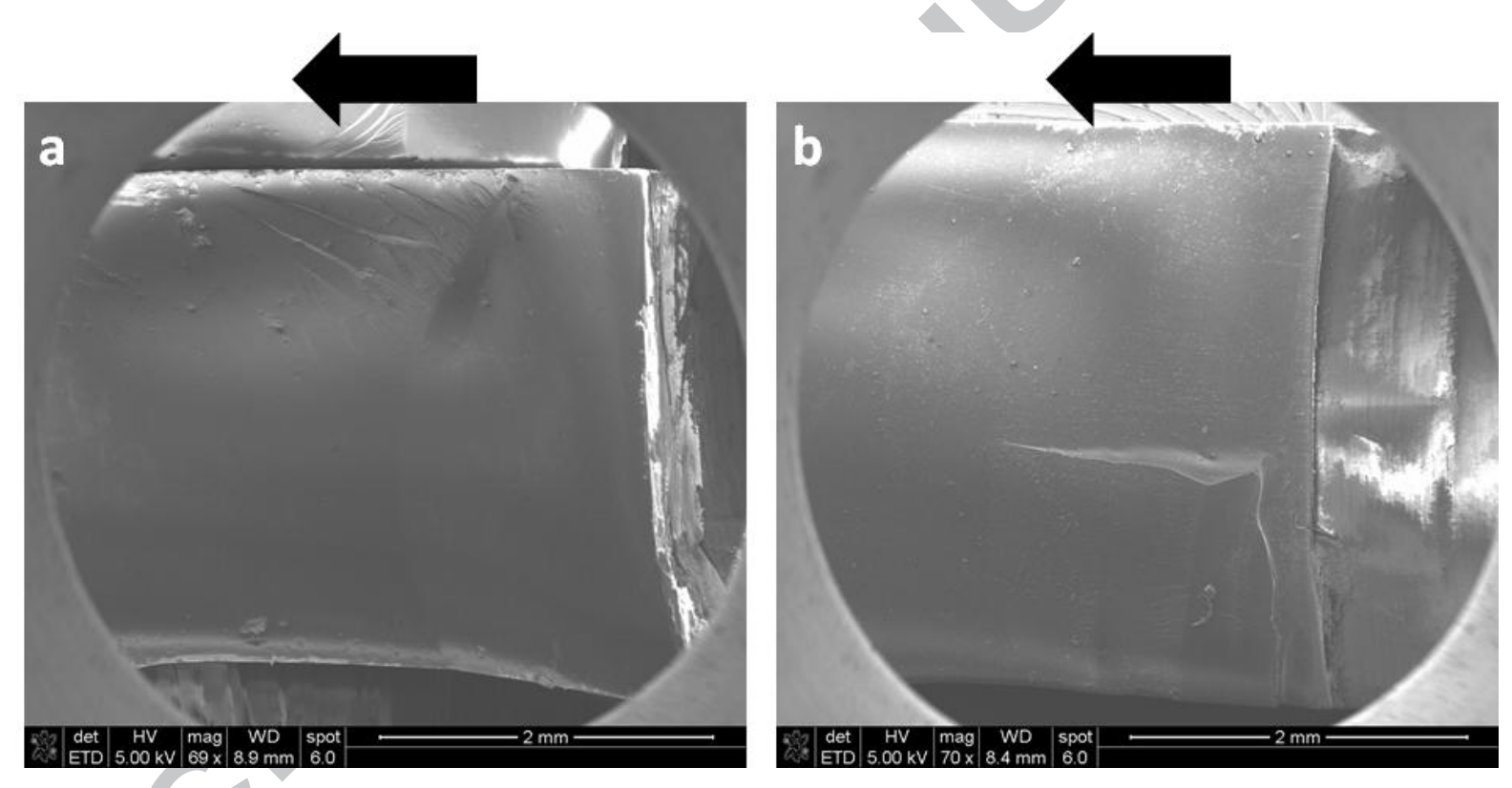

Figure 9. SEM images from fracture surface of a) pure epoxy and b) epoxy-silica aerogel nanocomposite (6 wt\%)taken close to the initial crack zone. Arrowhead indicates the direction of the crack propagation.

\section{Conclusion}

In this study, the effect of silica aerogel was investigated on the rheological, mechanical and thermal properties of epoxy nanocomposites. The rheological analysis showed that the viscosity of the nanocomposite suspension was increased by adding the silica aerogel content from $1 \mathrm{wt} \%$ to $6 \mathrm{wt} \%$. The observed sharp increase in viscosity indicated that the epoxy polymer chains is confined within the nano channel that increased the flow resistance of nanocomposite suspension. Moreover, adding the silica aerogels led to an increase in storage modulus $(11 \%), \operatorname{Tg}\left(5^{\circ} \mathrm{C}\right)$, Young's modulus $(35 \%)$, tensile strength $(62 \%)$ and toughness $(126 \%)$. Improved mechanical and thermal properties are attributed to the formation of an interpenetrating polymer network in the mesopores of silica aerogels. Two main mechanisms are identified to be the main mechanisms for improvement of the toughness of 
the epoxy silica aerogel-nanocomposite: (a) crack pinning and deflection, and (b) plastic deformation (debonding). 
Table 1. Properties of silica aerogel-epoxy nanocomposite.

\begin{tabular}{|c|c|c|c|c|c|c|c|c|c|c|c|}
\hline \multirow{2}{*}{$\begin{array}{l}\text { Nano- } \\
\text { composite }\end{array}$} & \multirow{2}{*}{$\begin{array}{c}\text { Aerogel } \\
\text { content } \\
\text { Wt.\% }\end{array}$} & \multicolumn{2}{|c|}{ Physical properties } & \multirow{2}{*}{$\begin{array}{c}\text { Rheological } \\
\text { properties }\end{array}$} & \multicolumn{2}{|c|}{ DMA } & \multirow{2}{*}{$\begin{array}{c}\text { DTGA } \\
\mathrm{T}_{\text {oncet }}\left({ }^{\circ} \mathrm{C}\right)\end{array}$} & \multicolumn{4}{|c|}{ Mechanical properties } \\
\hline & & $\begin{array}{l}\text { Specific } \\
\text { gravity }\end{array}$ & $\begin{array}{c}\text { Polymer } \\
\text { inside }\end{array}$ & & $\begin{array}{c}\mathrm{G}^{\prime}(\mathrm{GPa}) \\
\left(40^{\circ} \mathrm{C}\right)\end{array}$ & $\operatorname{Tg}\left({ }^{\circ} \mathrm{C}\right)$ & & $\begin{array}{l}\text { Tensile } \\
\text { Strength } \\
(\mathrm{MPa})\end{array}$ & $\begin{array}{c}\text { Young modulus } \\
(\mathrm{MPa})\end{array}$ & $\begin{array}{l}\text { Toughness } \\
\text { (mJ) }\end{array}$ & $\begin{array}{c}\text { Elongation at } \\
\text { break }(\%)\end{array}$ \\
\hline Ref & 0 & 1.196 & - & 15.2 & 0.93 & 149.6 & 428.3 & $29.8 \pm 0.05$ & $2010 \pm 1.41$ & $559.5 \pm 2.43$ & $1.5 \pm 0.04$ \\
\hline $\mathrm{O} 1$ & 1 & 1.193 & 4.67 & 18.7 & 1.01 & 152.1 & 435.9 & $34.5 \pm 0.16$ & $2188 \pm 3.33$ & $711.8 \pm 6.05$ & $1.6 \pm 0.04$ \\
\hline $\mathrm{O} 2$ & 2 & 1.194 & 12.55 & 27.7 & 1.02 & 153.3 & 441.1 & $43.2 \pm 0.17$ & $2311 \pm 5.06$ & $1072.1 \pm 5.60$ & $1.9 \pm 0.07$ \\
\hline $\mathrm{O} 4$ & 4 & 1.194 & 25.82 & 52 & 1.02 & 154.1 & 443.3 & $44.6 \pm 0.17$ & $2352 \pm 5.46$ & $1121.5 \pm 5.13$ & $1.9 \pm 0.07$ \\
\hline O6 & 6 & 1.195 & 39.73 & 73.3 & 1.03 & 154.8 & 445.6 & $48.3 \pm 0.15$ & $2709 \pm 3.30$ & $1265.0 \pm 4.12$ & $2.0 \pm 0.06$ \\
\hline
\end{tabular}




\section{Conflict of Interests}

There are no conflicts of interest.

\section{Acknowledgment}

We thank our colleagues Michel Barbezat, Matthias Koebel, Shanyu Zhao, Beatrice Fischer, Frank Winnefeld and Peter Winiger, who provided insight, expertise and assistance with the measurements and synthesis.

\section{References}

[1] R. E. Neisiany, J. K. Y. Lee, S. N. Khorasani, and S. Ramakrishna, "Self-healing and interfacially toughened carbon fibre-epoxy composites based on electrospun core-shell nanofibres," Journal of Applied Polymer Science, vol. 134, 2017.

[2] R. E. Neisiany, J. K. Y. Lee, S. N. Khorasani, and S. Ramakrishna, "Towards the development of self-healing carbon/epoxy composites with improved potential provided by efficient encapsulation of healing agents in core-shell nanofibers," Polymer Testing, vol. 62, pp. 79-87, 2017.

[3] R. E. Neisiany, J. K. Y. Lee, S. N. Khorasani, R. Bagheri, and S. Ramakrishna, "Facile strategy toward fabrication of highly responsive self-healing carbon/epoxy composites via incorporation of healing agents encapsulated in poly (methylmethacrylate) nanofiber shell," Journal of Industrial and Engineering Chemistry, 2017.

[4] H. Khoramishad and S. Razavi, "Metallic fiber-reinforced adhesively bonded joints," International Journal of Adhesion and Adhesives, vol. 55, pp. 114-122, 2014.

[5] S. Ahir, Y. Huang, and E. Terentjev, "Polymers with aligned carbon nanotubes: Active composite materials," Polymer, vol. 49, pp. 3841-3854, 2008.

[6] S. Pavlidou and C. Papaspyrides, "A review on polymer-layered silicate nanocomposites," Progress in polymer science, vol. 33, pp. 1119-1198, 2008.

[7] C. Chen, R. S. Justice, D. W. Schaefer, and J. W. Baur, "Highly dispersed nanosilica-epoxy resins with enhanced mechanical properties," Polymer, vol. 49, pp. 3805-3815, 2008.

[8] R. E. Neisiany, S. N. Khorasani, J. K. Y. Lee, M. Naeimirad, and S. Ramakrishna, "Interfacial toughening of carbon/epoxy composite by incorporating styrene acrylonitrile nanofibers," Theoretical and Applied Fracture Mechanics, vol. 95, pp. 242-247, 2018.

[9] M. A. Ver Meer, B. Narasimhan, B. H. Shanks, and S. K. Mallapragada, "Effect of mesoporosity on thermal and mechanical properties of polystyrene/silica composites," ACS Applied Materials \& Interfaces, vol. 2, pp. 41-47, 2009. 
[10] S. Razavi, M. Ayatollahi, E. Esmaeili, and L. da Silva, "Mixed-mode fracture response of metallic fiber-reinforced epoxy adhesive," European Journal of Mechanics-A/Solids, vol. 65, pp. 349-359, 2017.

[11] S. Razavi, M. Peron, J. Torgersen, and F. Berto, "The Effect of Interface Geometry on the Mechanical Behavior of Adhesive Joints," in Key Engineering Materials, 2017, pp. 256-259.

[12] R. E. Neisiany, S. N. Khorasani, M. Naeimirad, J. K. Y. Lee, and S. Ramakrishna, "Improving mechanical properties of carbon/epoxy composite by incorporating functionalized electrospun polyacrylonitrile nanofibers," Macromolecular Materials and Engineering, vol. 302, p. 1600551, 2017.

[13] S. Razavi, R. E. Neisiany, M. Ayatollahi, S. Ramakrishna, S. N. Khorasani, and F. Berto, "Fracture assessment of polyacrylonitrile nanofiber-reinforced epoxy adhesive," Theoretical and Applied Fracture Mechanics, 2017.

[14] S. Kango, S. Kalia, A. Celli, J. Njuguna, Y. Habibi, and R. Kumar, "Surface modification of inorganic nanoparticles for development of organic-inorganic nanocomposites-a review," Progress in Polymer Science, vol. 38, pp. 1232-1261, 2013.

[15] S. P. Samuel, S. Li, I. Mukherjee, Y. Guo, A. C. Patel, G. Baran, et al., "Mechanical properties of experimental dental composites containing a combination of mesoporous and nonporous spherical silica as fillers," dental materials, vol. 25, pp. 296-301, 2009.

[16] A. Zadhoush, R. Reyhani, and M. Naeimirad, "Evaluation of surface modification impact on PP/MWCNT nanocomposites by rheological and mechanical characterization, assisted with morphological image processing," Polymer Composites, doi:10.1002/pc.24799, 2008.

[17] M. Lenarda, G. Chessa, E. Moretti, S. Polizzi, L. Storaro, and A. Talon, "Toward the preparation of a nanocomposite material through surface initiated controlled/"living" radical polymerization of styrene inside the channels of MCM-41 silica," Journal of materials science, vol. 41, pp. 6305-6312, 2006.

[18] S. Salimian, A. Zadhoush, and A. Mohammadi, "A review on new mesostructured composite materials: Part I. synthesis of polymer-mesoporous silica nanocomposite," Journal of Reinforced Plastics and Composites, vol. 37, pp. 441-459, 2018.

[19] S. Salimian, A. Zadhoush, and A. Mohammadi, "A review on new mesostructured composite materials: Part II. Characterization and properties of polymer-mesoporous silica nanocomposite," Journal of Reinforced Plastics and Composites, vol. 37, pp. 738-769, 2018.

[20] M. Sibeko, M. Saladino, A. Luyt, and E. Caponetti, "Morphology and properties of poly (methyl methacrylate)(PMMA) filled with mesoporous silica (MCM-41) prepared by melt compounding," Journal of materials science, vol. 51, pp. 3957-3970, 2016.

[21] F.-A. Zhang, D.-K. Lee, and T. J. Pinnavaia, "PMMA-mesocellular foam silica nanocomposites prepared through batch emulsion polymerization and compression molding," Polymer, vol. 50, pp. 4768-4774, 2009.

[22] J. He, Y. Shen, D. G. Evans, and X. Duan, "Tailoring the performance of polymer composites via altering the properties of the intrapore polymers of MCM-48 nanocomposites as fillers," Composites Part A: Applied Science and Manufacturing, vol. 37, pp. 379-384, 2006.

[23] M. L. Cerrada, E. Pérez, J. P. Lourenço, J. M. Campos, and M. R. Ribeiro, "Hybrid HDPE/MCM41 nanocomposites: Crystalline structure and viscoelastic behaviour," Microporous and Mesoporous Materials, vol. 130, pp. 215-223, 2010. 
[24] N. Wang, Q. Fang, Y. Shao, and J. Zhang, "Microstructure and properties of polypropylene composites filled with co-incorporation of MCM-41 (with template) and OMMT nanoparticles prepared by melt-compounding," Materials Science and Engineering: A, vol. 512, pp. 32-38, 2009.

[25] J. Lin and X. Wang, "Novel low-k polyimide/mesoporous silica composite films: Preparation, microstructure, and properties," Polymer, vol. 48, pp. 318-329, 2007.

[26] F. F. Fang, H. J. Choi, and W. S. Ahn, "Electroactive response of mesoporous silica and its nanocomposites with conducting polymers," Composites Science and Technology, vol.69, pp. 2088-2092, 2009.

[27] Q. Cheng, V. Pavlinek, C. Li, A. Lengalova, Y. He, and P. Saha, "Synthesis and characterization of new mesoporous material with conducting polypyrrole confined in mesoporous silica," Materials chemistry and physics, vol. 98, pp. 504-508, 2006.

[28] N. Suzuki, S. Kiba, and Y. Yamauchi, "Fabrication of mesoporous silica KIT-6/polymer composite and its low thermal expansion property," Materials letters, vol. 65, pp. 544-547, 2011.

[29] J. Jiao, X. Sun, and T. J. Pinnavaia, "Mesostructured silica for the reinforcement and toughening of rubbery and glassy epoxy polymers," Polymer, vol. 50, pp. 983-989, 2009.

[30] I. Park, H.-g. Peng, D. W. Gidley, S. Xue, and T. J. Pinnavaia, "Epoxy- silica mesocomposites with enhanced tensile properties and oxygen permeability," Chemistry of materials, vol. 18 , pp. 650-656, 2006.

[31] S. Kiba, Y. Okawauchi, T. Yanagihara, M. Murakami, T. Shimizu, and Y. Yamauchi, "Mesoporous Silica/Polymer Composites Utilizing Intelligent Caps onto Mesopore Walls toward Practical Low-Dielectric Materials," Chemistry-An Asian Journal, vol. 4, pp. 17981801, 2009.

[32] Z. T. Mazraeh-shahi, A. M. Shoushtari, M. Abdouss, and A. R. Bahramian, "Relationship analysis of processing parameters with micro and macro structure of silica aerogel dried at ambient pressure," Journal of Non-Crystalline Solids, vol. 376, pp. 30-37, 2013.

[33] H. Maleki, L. Durães, and A. Portugal, "An overview on silica aerogels synthesis and different mechanical reinforcing strategies," Journal of Non-Crystalline Solids, vol. 385, pp. 55-74, 2014.

[34] S. Salimian, A. Zadhoush, M. Naeimirad, R. Kotek, and S. Ramakrishna, "A review on aerogel: 3D nanoporous structured fillers in polymer-based nanocomposites," Polymer Composites, DOI: 10.1002/pc.24412, 2017.

[35] H. Najafi, A. Zadhoush, Z. Talebi, and S. P. Rezazadeh Tehrani, "Influence of porosity and aspect ratio of nanoparticles on the interface modification of glass/epoxy composites," Polymer Composites, 2017.

[36] D. Ge, L. Yang, Y. Li, and J. Zhao, "Hydrophobic and thermal insulation properties of silica aerogel/epoxy composite," Journal of Non-Crystalline Solids, vol. 355, pp. 2610-2615, 2009.

[37] N. Gupta and W. Ricci, "Processing and compressive properties of aerogel/epoxy composites," Journal of materials processing technology, vol. 198, pp. 178-182, 2008.

[38] S. Salimian, A. Zadhoush, Z. Talebi, B. Fischer, P. Winiger, F. Winnefeld, et al., "Silica AerogelEpoxy Nanocomposites: Understanding Epoxy Reinforcement in Terms of Aerogel Surface Chemistry and Epoxy-Silica Interface Compatibility," ACS Applied Nano Materials, DOI: 10.1021/acsanm.8b00941, 2018. 
[39] S. T. M. f. T. P. o. P. STM D638-14, ASTM International, West Conshohocken, PA, 2014, www.astm.org, DOI: 10.1520/D0638-14.

[40] Z. T. Mazraeh-Shahi, A. M. Shoushtari, A. R. Bahramian, and M. Abdouss, "Synthesis, pore structure and properties of polyurethane/silica hybrid aerogels dried at ambient pressure," Journal of Industrial and Engineering Chemistry, vol. 21, pp. 797-804, 2015.

[41] Z. T. Mazraeh-shahi, A. M. Shoushtari, A. R. Bahramian, and M. Abdouss, "Synthesis, structure and thermal protective behavior of silica aerogel/PET nonwoven fiber composite," Fibers and Polymers, vol. 15, pp. 2154-2159, 2014.

[42] G. Reichenauer, "Structural characterization of aerogels," in Aerogels Handbook, ed: Springer, 2011, pp. 449-498.

[43] S. Kiba, N. Suzuki, Y. Okawauchi, and Y. Yamauchi, "Prototype of low thermal expansion materials: fabrication of mesoporous silica/polymer composites with densely filled polymer inside mesopore space," Chemistry-An Asian Journal, vol. 5, pp. 2100-2105, 2010.

[44] N. Suzuki, S. Kiba, and Y. Yamauchi, "Bimodal filler system consisting of mesoporous silica particles and silica nanoparticles toward efficient suppression of thermal expansion in silica/epoxy composites," Journal of Materials Chemistry, vol. 21, pp. 14941-14947, 2011.

[45] M. Naeimirad, A. Zadhoush, R. Kotek, R. Esmaeely Neisiany, S. Nouri Khorasani, and S. Ramakrishna, "Recent advances in core/shell bicomponent fibers and nanofibers: A review," Journal of Applied Polymer Science, vol. 135, p. 46265, 2018.

[46] Q. Guo, P. Zhu, G. Li, L. Huang, Y. Zhang, D. D. Lu, et al., "One-pot synthesis of bimodal silica nanospheres and their effects on the rheological and thermal-mechanical properties of silica-epoxy composites," RSC Advances, vol. 5, pp. 50073-50081, 2015.

[47] J.-H. Lee, C.-M. Um, and I.-b. Lee, "Rheological properties of resin composites according to variations in monomer and filler composition," Dental Materials, vol. 22, pp. 515-526, 2006.

[48] A. K. Garakani, N. Mostoufi, F. Sadeghi, H. Fatourechi, M. Sarrafzadeh, and M. Mehrnia, "Comparison between different models for rheological characterization of activated sludge," Journal of Environmental Health Science \& Engineering, vol. 8, pp. 255-264, 2011.

[49] C. Chen, H. Wang, Y. Xue, Z. Xue, H. Liu, X. Xie, et al., "Structure, rheological, thermal conductive and electrical insulating properties of high-performance hybrid epoxy/nanosilica/AgNWs nanocomposites," Composites Science and Technology, vol. 128, pp. 207-214, 2016.

[50] H. Xia and M. Song, "Intercalation and exfoliation behaviour of clay layers in branched polyol and polyurethane/clay nanocomposites," Polymer international, vol. 55, pp. 229-235, 2006. C.-F. Cheng, H.-H. Cheng, P.-W. Cheng, and Y.-J. Lee, "Effect of reactive channel functional groups and nanoporosity of nanoscale mesoporous silica on properties of polyimide composite," Macromolecules, vol. 39, pp. 7583-7590, 2006.

[52] J. Jiao, L. Wang, G. Wu, P. Lv, and Y. Cui, "Effects of framework structure and coupling modification on the properties of mesoporous silica/poly (methyl methacrylate) composites," Journal of Reinforced Plastics and Composites, vol. 34, pp. 222-231, 2015.

[53] M. Run, S. Wu, D. Zhang, and G. Wu, "A polymer/mesoporous molecular sieve composite: Preparation, structure and properties," Materials Chemistry and Physics, vol. 105, pp. 341347, 2007. 
[54] J. Lin and X. Wang, "New type of low-dielectric composites based on o-cresol novolac epoxy resin and mesoporous silicas: fabrication and performances," Journal of Materials Science, vol. 43, pp. 4455-4465, 2008.

[55] J. Lin and X. Wang, "Preparation, microstructure, and properties of novel low-k brominated epoxy/mesoporous silica composites," European Polymer Journal, vol. 44, pp. 1414-1427, 2008.

[56] I. Park and T. J. Pinnavaia, "Mesocellular silica foam as an epoxy polymer reinforcing agent," Advanced Functional Materials, vol. 17, pp. 2835-2841, 2007.

[57] H. Shi, T. Lan, and T. J. Pinnavaia, "Interfacial effects on the reinforcement properties of polymer- organoclay nanocomposites," Chemistry of materials, vol. 8, pp. 1584-1587, 1996.

[58] A. Kinloch and A. Taylor, "The toughening of cyanate-ester polymers Part I Physical modification using particles, fibres and woven-mats," Journal of materials science, vol. 37, pp. 433-460, 2002.

[59] M. Naeimirad, A. Zadhoush, R. E. Neisiany, S. Ramakrishna, S. Salimian, and A. A. Leal, "Influence of microfluidic flow rates on the propagation of nano/microcracks in liquid core and hollow fibers," Theoretical and Applied Fracture Mechanics, vol. 96, pp. 83-89, 2018.

[60] T. Hsieh, A. Kinloch, K. Masania, A. Taylor, and S. Sprenger, "The mechanisms and mechanics of the toughening of epoxy polymers modified with silica nanoparticles," Polymer, vol. 51, pp. 6284-6294, 2010.

[61] M. Ayatollahi, A. Nemati Giv, S. Razavi, and H. Khoramishad, "Mechanical properties of adhesively single lap-bonded joints reinforced with multi-walled carbon nanotubes and silica nanoparticles," The Journal of Adhesion, vol. 93, pp. 896-913, 2017.

[62] A. Zeinedini, M. M. Shokrieh, and A. Ebrahimi, "The effect of agglomeration on the fracture toughness of CNTs-reinforced nanocomposites," Theoretical and Applied Fracture Mechanics, 2018.

[63] W. Liu, R. Zhou, H. L. S. Goh, S. Huang, and X. Lu, "From waste to functional additive: toughening epoxy resin with lignin," ACS applied materials \& interfaces, vol. 6, pp. 5810$5817,2014$. 


\section{Highlights}

- Aerogels can improve the mechanical properties of epoxy-based nanocomposites due to the unique properties such as 3-dimensional nanoporous structure and high surface area.

- In this study, the effect of silica aerogel was investigated on the rheological, mechanical and thermal properties of the epoxy nanocomposite.

- Two main mechanisms are identified to be the main mechanisms for improvement of the toughness of the epoxy silica aerogel-nanocomposite: (a) crack pinning and deflection, and (b) plastic deformation (debonding). 